\title{
Qualidade e equidade no ensino fundamental público do Ceará ${ }^{2}$
}

* Mestre em Economia Internacional e

Desenvolvimento pela

Universidade Paris Dauphine.

E-mail:

frepadilha@hotmail.com

** Mestre em Teoria Econômica pela FEA-USP e pesquisadora do Cenpec. E-mail:

paula.kasmisrki@cenpec.org.br

*** Graduando em Ciências Sociais pela FFLCH-USP e estagiário do Cenpec. E-mail: guilherme.correa@cenpec.org.br

$\star \star \star \star$ Mestre em Sociologia pela Unicamp, doutora em Educação pela FE-USP e coordenadora-adjunta de Desenvolvimento de Pesquisas do Cenpec. E-mail: vanda.ribeiro@cenpec.org.br

$\star \star \star \star \star$ Doutor em Educação pela UFMG, é professor do Programa de Pós-Graduação em Educação da mesma Universidade e coordenador de Desenvolvimento de Pesquisas do Cenpec. E-mail: antonio.batista@cenpec.org.br
Frederica Padilha* Paula Reis Kasmisrki** Guilherme Zanelato Corrêa*** Vanda Mendes Ribeiro ${ }^{\star \star \star \star}$

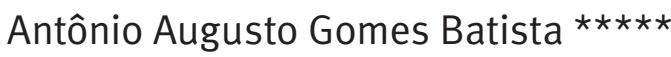

Resumo: Este artigo procurou analisar a evolução e a dispersão do Ideb entre 2005 e 2011 nas duas etapas do ensino fundamental na rede pública do estado do Ceará, assim como essa evolução vem incidindo na equidade entre as escolas entre 2007 e 2011. A equidade foi analisada considerando a evolução do Ideb das escolas em relação ao nível socioeconômico médio de seu corpo discente e aos diferentes níveis de centralidade dos municípios, conforme tipologia criada pelo IBGE. A análise aponta que o Ideb médio das escolas, municípios e Credes (órgãos regionais da Secretaria de Educação do Estado do Ceará) aumentou sem concomitante aumento da dispersão em ambas as etapas do ensino fundamental. Nos anos iniciais, observa-se um ganho de equidade, verificado por uma redução da influência do nível socioeconômico na explicação do Ideb.

Palavras-chave: Qualidade da educação. Equidade. Ideb.

Uma primeira versão deste artigo foi apresentada na VII Reunião da Associação Brasileira de Avaliação Educacional (Abave), realizada em 2013 em Brasília. A versão atual passou por modificações substanciais.

Os autores agradecem as contribuições de Hamilton Harley de Carvalho-Silva e Luciana Alves dadas ao longo da elaboração da primeira versão do artigo. Agradecem também a oportunidade de discussão da mesma versão com Paula Louzano e Romualdo Portela de Oliveira. 


\section{INTRODUÇÃO}

O Ceará é um estado que vem alcançando destaque no contexto educacional brasileiro em função de sua expressiva evolução do Índice de Desenvolvimento da Educação Básica (Ideb³) no ensino fundamental (EF). Tal constatação foi estabelecida em trabalhos anteriores da Coordenação de Desenvolvimento de Pesquisas do Centro de Estudos e Pesquisas em Educação, Cultura e Ação Comunitária (Cenpec) - Padilha et al. (2011), Padilha et al. (2012) e Padilha e Batista (2013). Nesses trabalhos, que focavam nos anos finais do EF, os municípios cearenses se destacaram por apresentarem altos valores de Ideb relativamente ao padrão da região Nordeste. No presente artigo, pretende-se verificar se a evolução do Ideb se deu de forma equânime entre os diferentes municípios e escolas do estado, tanto no EF 1 como no 2.

O conceito de equidade é compreendido à luz de Dubet (2009), que afirma que nas sociedades democráticas contemporâneas, que produzem permanentemente desigualdades e valorizam igualdade e liberdade, a equidade depende da distribuição de bens que favorecem prioritariamente a população que tem menos recursos socioeconômicos.

Com base nesse conceito de equidade, pode-se afirmar que em sistemas mais justos de educação básica, a política educacional deveria ser capaz de levar alunos, escolas, localidades ou territórios com menor nível socioeconômico a níveis adequados de desempenho escolar. Essa situação implicaria, necessariamente, em correção da tendência de impacto da desigualdade social sobre as oportunidades de aprendizagem (BROOKE; SOARES, 2008).

A qualidade é mensurada por meio do Ideb, embora o estudo reconheça que esse indicador não contém todas as dimensões necessárias ao conceito de

O Ideb, índice criado em 2007 pelo governo federal, é composto por indicadores de fluxo escolar (Censo Escolar) e de desempenho dos alunos (aferidos pela Prova Brasil e pelo Saeb). A Prova Brasil é um exame de larga escala de caráter censitário (excluindo as escolas com menos de 20 alunos matriculados na série avaliada) criado pelo Inep em 2005 no âmbito do Sistema de Avaliação da Educação Básica (Saeb). É aplicada para avaliar competências esperadas em Língua Portuguesa e Matemática junto a alunos das $4^{\underline{a}}$ séries $/ 5^{\circ}$ anos e das $8^{\underline{a}}$ séries $/ 9^{\circ}$ anos das redes e escolas municipais, estaduais e federais de todo o país. 0 Saeb produz informações a respeito da realidade educacional brasileira e, especificamente, por regiões, redes de ensino pública e privada nos estados e no Distrito Federal, por meio de exame bienal de proficiência em Matemática e Língua Portuguesa (leitura). É aplicado em amostras de alunos de $4^{\underline{a}}$ e $8^{\underline{a}}$ séries do ensino fundamental e da $3^{\underline{a}}$ série do ensino médio. 
qualidade de educação, conforme aponta Oliveira (2010). Seu uso se justifica por sua capacidade de lidar, ao mesmo tempo, com duas dimensões essenciais para a compreensão do processo de massificação do ensino fundamental no Brasil: o fluxo escolar e a aprendizagem de habilidades básicas de Língua Portuguesa e Matemática ${ }^{4}$.

Este artigo descreve resultados parciais de uma pesquisa ainda em andamento, pois para desvelar de forma mais completa a evolução da equidade no estado do Ceará tal como está sendo compreendida, é preciso ainda uma investigação sobre o nível socioeconômico de cada aluno.

Os principais resultados encontrados foram:

1. O Ideb das escolas, municípios e Credes cearenses têm crescido desde 2005 e tal crescimento não parece estar acompanhado do aumento da dispersão do indicador.

2. No EF1 houve aumento da equidade, pois a influência do NSE diminui no período considerado (2007 e 2011).

3. Já no EF2 só foram observadas melhorias na igualdade nos municípios de centralidade intermediária, conforme classificação do IBGE.

4. Os resultados de Fortaleza, em ambas as etapas do EF, destoam do padrão dos outros municípios, pois o peso do NSE na metrópole parece ser maior.

O texto está dividido em quatro partes. A primeira descreve a metodologia utilizada; a segunda se dedica à análise da evolução da média e da dispersão do Ideb entre escolas, municípios e unidades de gestão de nível estadual; a seguinte analisa a evolução da equidade; e a quarta apresenta a conclusão.

\section{Metodologia}

Serão feitos três exercícios neste artigo: (i) uma análise descritiva do Ideb para avaliar sua evolução e dispersão; (ii) a estimação de modelos multinível para investigar a evolução da equidade; e (iii) uma análise dos componentes do Ideb.

Para avaliar a evolução e a dispersão do Ideb, utilizaram-se estatísticas descritivas da distribuição do indicador tendo como referência três unidades de análise: os órgãos que representam a Secretaria de Educação Estadual nas diversas regiões do estado - as Coordenadorias Regionais de Desenvolvimento da Educação (Credes) -, os municípios e as escolas. Analisamos o período

Sobre esse assunto, ver Ribeiro (1991) e Oliveira e Araújo (2005). 
desde o surgimento do Ideb (2005) até sua última divulgação (2011).

Posteriormente, foram estimados modelos multiníveis, para os anos 2007 e 2011, com o intuito de analisar a evolução da equidade na rede pública de ensino fundamental do estado ${ }^{5}$. Para tanto, relacionamos o Ideb de cada escola, dos referidos anos, e dois distintos indicadores de nível socioeconômico: (1) a classificação do IBGE (2007) que evidencia o grau de influência socioeconômica e o nível de desenvolvimento local dos municípios; (2) e o nível socioeconômico dos alunos matriculados nas escolas de ensino fundamental das redes estadual e municipal do Ceará.

Em 2007, municípios de todo o Brasil foram classificados pelo IBGE em cinco grandes níveis de hierarquia, subdivididos em dois ou três subníveis, que vão desde centros locais (cidades com menos de 10 mil habitantes) a grande metrópole nacional (São Paulo). No presente artigo, optamos por agregar os municípios do Ceará em: (i) metrópole (Fortaleza), (ii) capitais regionais e centros sub-regionais (seis municípios) e (iii) região metropolitana de Fortaleza e Cariri (exceto Fortaleza e Juazeiro do Norte, esse último incluído na categoria (ii)), centros de zona e centros locais (177 municípios).

A agregação das categorias de centralidade se justifica por questões relacionadas à estabilidade das ordenações dos municípios ao longo do tempo. Por conta do processo de ocupação do território, os níveis hierárquicos mais altos são mais estáveis, enquanto as hierarquias intermediárias e baixas sofreram mais mudanças desde 1966, ano da primeira publicação sobre regiões de influência das cidades (IBGE, 2007). O fato de cidades das regiões metropolitanas estarem no grupo de centralidade mais baixa se dá porque dos 21 municípios metropolitanos cearenses, 12 foram classificados pelo IBGE como centros locais e os outros nove não possuem classificação.

Grosso modo, o nível de centralidade de um município é função da presença de órgãos do Estado e sedes de empresas, atividades de comércio e serviços, atividade financeira, instituições de ensino superior, serviços de saúde, Internet, redes de televisão aberta e transporte aéreo (IBGE, 2007).

A seguir apresentamos algumas características das cidades por tipo de centralidade no estado do Ceará para os anos de 2000 e $2010^{6}$. Pelas tabelas 1 e 2 nota-se que os municípios do grupo centros de zona e centros locais

5 Os microdados de 2005 da Prova Brasil, necessários para o cálculo do indicador de nível socioeconômico, não estão disponíveis ao público.

$6 \quad$ Não temos informações especificamente para 2007 e 2011, pois a fonte de dados municipais oficial é o Censo Demográfico do IBGE, coletado de dez em dez anos. 
são os de menor nível socioeconômico e desenvolvimento. Em seguida, aparecem aqueles classificados como capitais regionais e centros subregionais e depois a metrópole. Observa-se que quanto maior o nível social e econômico do grupo, maior é a desigualdade de renda, medida pelo índice de Gini. Comparando os grupos no tempo, percebe-se uma melhora geral das condições de vida da população, com redução da pobreza e da desigualdade.

A trajetória dos indicadores de nível socioeconômico do estado do Ceará (\% de pobres, \% de população rural, IDH, índice de Gini e renda per capita) não parece ter destoado do padrão observado na região Nordeste. Ou seja, também aconteceram melhorias semelhantes nas condições de vida dos outros estados nordestinos. Tal fato é relevante, pois o Ceará conseguiu resultados educacionais melhores em relação aos estados, mesmo tendo evolução parecida em termos socioeconômicos.

O nível socioeconômico (NSE) dos alunos utilizado nesta pesquisa foi estimado a partir dos microdados da Prova Brasil 2007 e 2011, com base no Critério de Classificação Econômica Brasil, conhecido como Critério Brasil, da Associação Brasileira de Empresas de Pesquisa (Abep), vigente de 2008 a 2011. O objetivo do Critério Brasil é estimar o poder de compra de pessoas e famílias residentes na área urbana e, para tanto, classifica os indivíduos em oito classes econômicas - A1, A2, B1, B2, C1, C2, D e E - com potencial de consumo decrescente (ABEP, 2013).

Tendo em vista que no Ceará um quarto da população reside na área rural e para fins de validação do indicador de NSE7 , calculamos a correlação da renda média das famílias com estudantes do EF na rede pública por município em 2010 com o indicador de NSE referente aos anos de 2007 e 2010. Esse exercício mostrou que o indicador parece descrever bem o nível socioeconômico dos municípios cearenses, conforme mensurado pela renda domiciliar per capita. A renda dos municípios se correlaciona da forma esperada e significativa (a $1 \%$ ) com os percentuais de alunos nas classes (agrupadas em A e B, C, D, E; ver Tabela 3).

O indicador da Abep foi construído com base em dados de regiões metropolitanas (Porto Alegre, Curitiba, São Paulo, Rio de Janeiro, Belo Horizonte, Salvador, Recife, Fortaleza, Distrito Federal). Como no Ceará há um quarto da população em área rural, poder-se-ia questionar se a aplicação do Critério Brasil é adequada. 
Tabela 1. Características dos municípios cearenses por tipo de centralidade em 2010

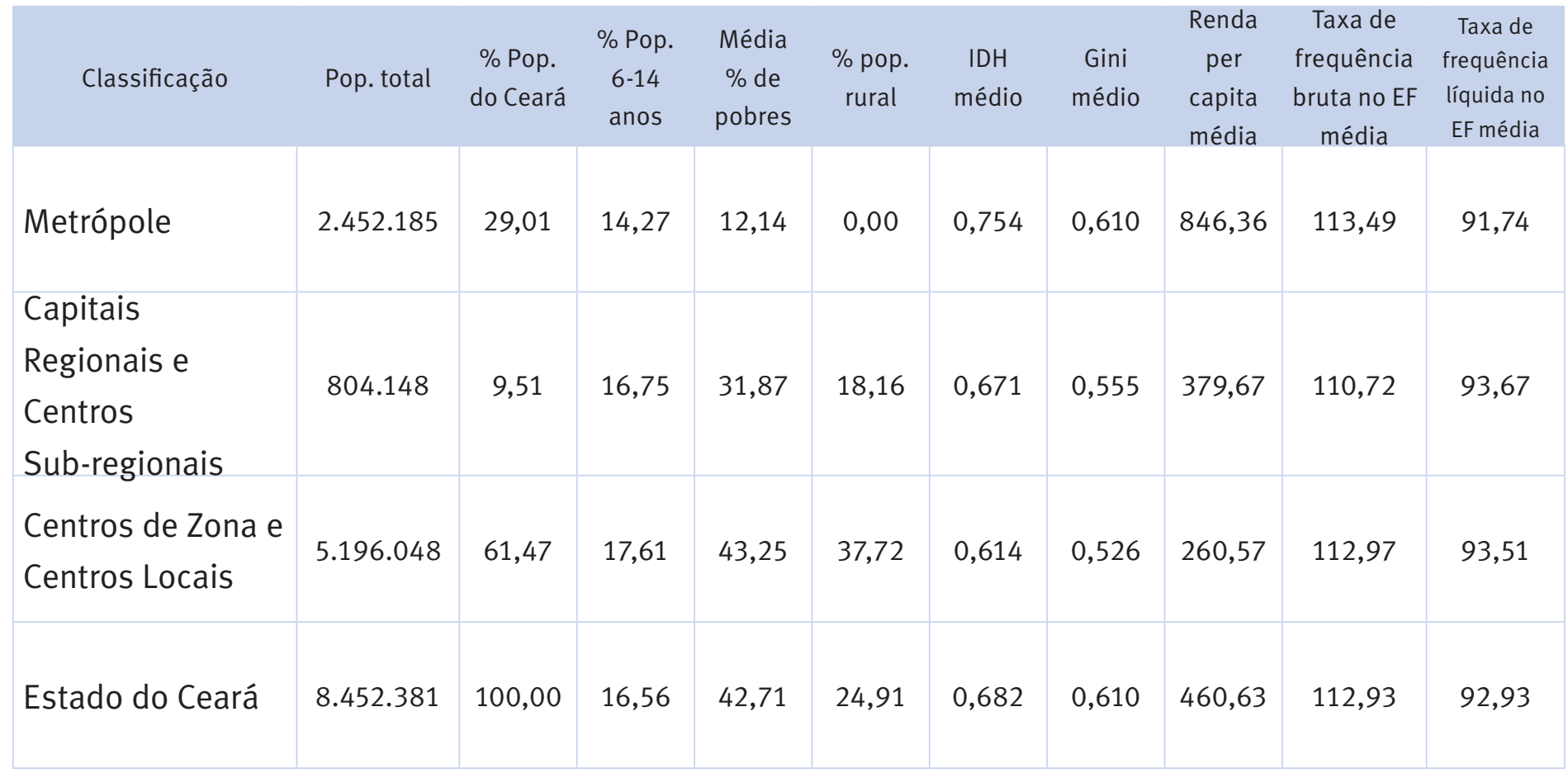

Fonte: Atlas 2013/Pnud.

Tabela 2. Características dos municípios cearenses por tipo de centralidade em 2000

\begin{tabular}{|c|c|c|c|c|c|c|c|c|c|c|}
\hline Classificação & Pop. total & $\begin{array}{c}\text { \% Pop. } \\
\text { do Ceará }\end{array}$ & $\begin{array}{c}\% \text { Pop. } \\
6-14 \\
\text { anos }\end{array}$ & $\begin{array}{l}\text { Média } \\
\% \text { de } \\
\text { pobres }\end{array}$ & $\begin{array}{c}\% \text { pop. } \\
\text { rural }\end{array}$ & $\begin{array}{c}\text { IDH } \\
\text { médio }\end{array}$ & $\begin{array}{l}\text { Gini } \\
\text { médio }\end{array}$ & $\begin{array}{l}\text { Renda } \\
\text { per } \\
\text { capita } \\
\text { média }\end{array}$ & $\begin{array}{c}\text { Taxa de } \\
\text { frequência } \\
\text { bruta no EF } \\
\text { média }\end{array}$ & $\begin{array}{l}\text { Taxa de } \\
\text { frequência } \\
\text { líquida no } \\
\text { EF média }\end{array}$ \\
\hline Metrópole & 2.135 .544 & 28,74 & 17,81 & 27,54 & 0,00 & 0,652 & 0,640 & 610,48 & 120,58 & 92,00 \\
\hline $\begin{array}{l}\text { Capitais } \\
\text { Regionais e } \\
\text { Centros } \\
\text { Sub-regionais }\end{array}$ & 688.419 & 9,26 & 20,38 & 53,68 & 21,27 & 0,522 & 0,607 & 248,60 & 120,07 & 90,22 \\
\hline $\begin{array}{l}\text { Centros de Zona e } \\
\text { Centros Locais }\end{array}$ & $4,606.704$ & 62,00 & 21,55 & 66,60 & 42,74 & 0,445 & 0,589 & 158,05 & 123,29 & 90,31 \\
\hline Estado do Ceará & 7.430 .667 & 100,00 & 20,36 & 65,96 & 28,47 & 0,541 & 0,670 & 310,21 & 121,99 & 90,71 \\
\hline
\end{tabular}

Fonte: Atlas 2013/Pnud. 
Tabela 3. Correlação entre a renda domiciliar per capita de domicílios com estudantes de ensino fundamental em 2010 e percentual de alunos por classe econômica baseada no Critério Brasil.

\begin{tabular}{|c|c|c|}
\hline Ano & Classe de renda & Correlação \\
\hline \multirow{4}{*}{2011} & $\mathrm{~A}$ e B & 0,6651 \\
\hline & $\mathrm{C}$ & 0,5853 \\
\hline & $\mathrm{D}$ & $-0,7071$ \\
\hline & $E$ & $-0,5496$ \\
\hline \multirow{4}{*}{2007} & $A$ e $B$ & 0,5149 \\
\hline & $C$ & 0,6283 \\
\hline & $\mathrm{D}$ & $-0,6531$ \\
\hline & $E$ & $-0,4393$ \\
\hline
\end{tabular}

Fonte: Microdados do Censo Demográfico 2010/IBGE; Microdados da Prova Brasil 2007 e 2011.

Na Tabela 3, vemos que quanto maiores os percentuais de alunos nas classes A, B e C nos municípios, maior é a renda domiciliar per capita; e quanto maiores os percentuais de alunos nas classes $\mathrm{D}$ e $\mathrm{E}$, menor é a renda.

O indicador de NSE usado nos modelos multiníveis, descritos na seção 4, é o percentual por escola de estudantes de $5^{\circ}$ e $9^{\circ}$ ano do ensino fundamental que estavam nas classes A e B, C, D, E, para cada ano analisado. Os dados da Tabela 4 confirmam a tendência dos indicadores socioeconômicos das tabelas 1 e 2 quanto à distribuição das classes em função dos grupos de municípios.

Tabela 4. Percentual de alunos por classe econômica e renda domiciliar per capita nos grupos de municípios

\begin{tabular}{ccccc}
\multirow{2}{*}{ Ano } & Classe de & \multicolumn{4}{c}{$\begin{array}{c}\text { Centralidade } \\
\text { renda }\end{array}$} & Metrópole & $\begin{array}{c}\text { Capitais Regionais e } \\
\text { Centros Sub-regionais }\end{array}$ & $\begin{array}{c}\text { Centros de Zna e } \\
\text { Centros Locais }\end{array}$ \\
\cline { 2 - 5 } 2011 & A e B & $18,26 \%$ & $11,54 \%$ & $10,18 \%$ \\
\cline { 2 - 5 } & C & $67,96 \%$ & $65,81 \%$ & $60,23 \%$ \\
\cline { 2 - 5 } & D & $12,58 \%$ & $20,04 \%$ & $25,40 \%$ \\
\hline \multirow{2}{*}{2007} & $1,20 \%$ & $2,61 \%$ & $4,19 \%$ \\
\cline { 2 - 5 } & A e B & $14,30 \%$ & $9,17 \%$ & $8,06 \%$ \\
\cline { 2 - 5 } & D & $61,41 \%$ & $55,19 \%$ & $48,55 \%$ \\
\hline \multirow{2}{*}{2010} & $\begin{array}{c}\text { Denda } \\
\text { domiciliar } \\
\text { per capita }\end{array}$ & $83,68 \%$ & $29,46 \%$ & $34,43 \%$ \\
\hline
\end{tabular}

Fonte: Microdados do Censo Demográfico 2010/IBGE; Microdados da Prova Brasil 2007 e 2011. 


\section{A distribuição do Ideb nas CoORdenadorias Regionais de DesenVolvimento da EduCAÇão (CREDES) ${ }^{8}$, MUNicípIOS E ESCOlAS}

Esta seção pretende descrever a distribuição do Ideb das escolas e do Ideb médio dos municípios e Credes ao longo do período 2005 a 2011. Esse exercício tem por objetivo verificar como se comportou, de maneira geral, a evolução e a dispersão do Ideb. Nas figuras 1 e 2 constam os histogramas e densidades de kernel $^{9}$ dos Idebs das escolas por ano.

A análise descritiva da distribuição do Ideb das escolas no EF indica que, apesar do crescimento da média (e do desvio padrão), a dispersão do indicador nas duas etapas não se elevou. Percebe-se que, nos anos iniciais do EF, as distribuições têm se deslocado para a direita, com tendência de alongamento da cauda direita. Este último fato também pode ser apreendido na Tabela 5, olhando a assimetria, que é positiva e crescente ao longo do período. Apesar do prolongamento da cauda à direita, a curtose nos diz que a distribuição está ficando mais concentrada ao redor da média (pelo menos de 2005 ou 2007 em relação a 2011).

A distribuição de Ideb das escolas do EF2 também está se deslocando para a direita, porém com um prolongamento mais leve da cauda direita. Sua curtose indica que seu grau de achatamento está relativamente constante no tempo. O mesmo padrão geral apontado para as escolas do EF1 se mantém para o Ideb médio por municípios e Credes do EF 1 e 2 (ver tabelas 5 e 6).

\footnotetext{
As 21 Credes foram criadas em 1996 para substituir as 14 Delegacias Regionais de Ensino (DRE), e assumiram funções gerenciais nas áreas de recursos humanos, financeiros e atribuições nas áreas de desenvolvimento do ensino e da gestão escolar, tanto da rede estadual quanto das redes municipais. Cada Crede é responsável pela gestão das redes de um grupo de municípios, agrupados regionalmente. Como mostram Padilha e Batista (2013), atualmente, dentro do sistema de descentralização da educação cearense, as Credes parecem ser importantes atores na transposição das políticas e diretrizes educacionais do estado para os municípios.

9 Tanto o histograma quanto a densidade de kernel são formas não paramétricas de estimar densidades de probabilidade, que são funções que expressam as frequências relativas de uma variável (HANSEN, 2009).
} 

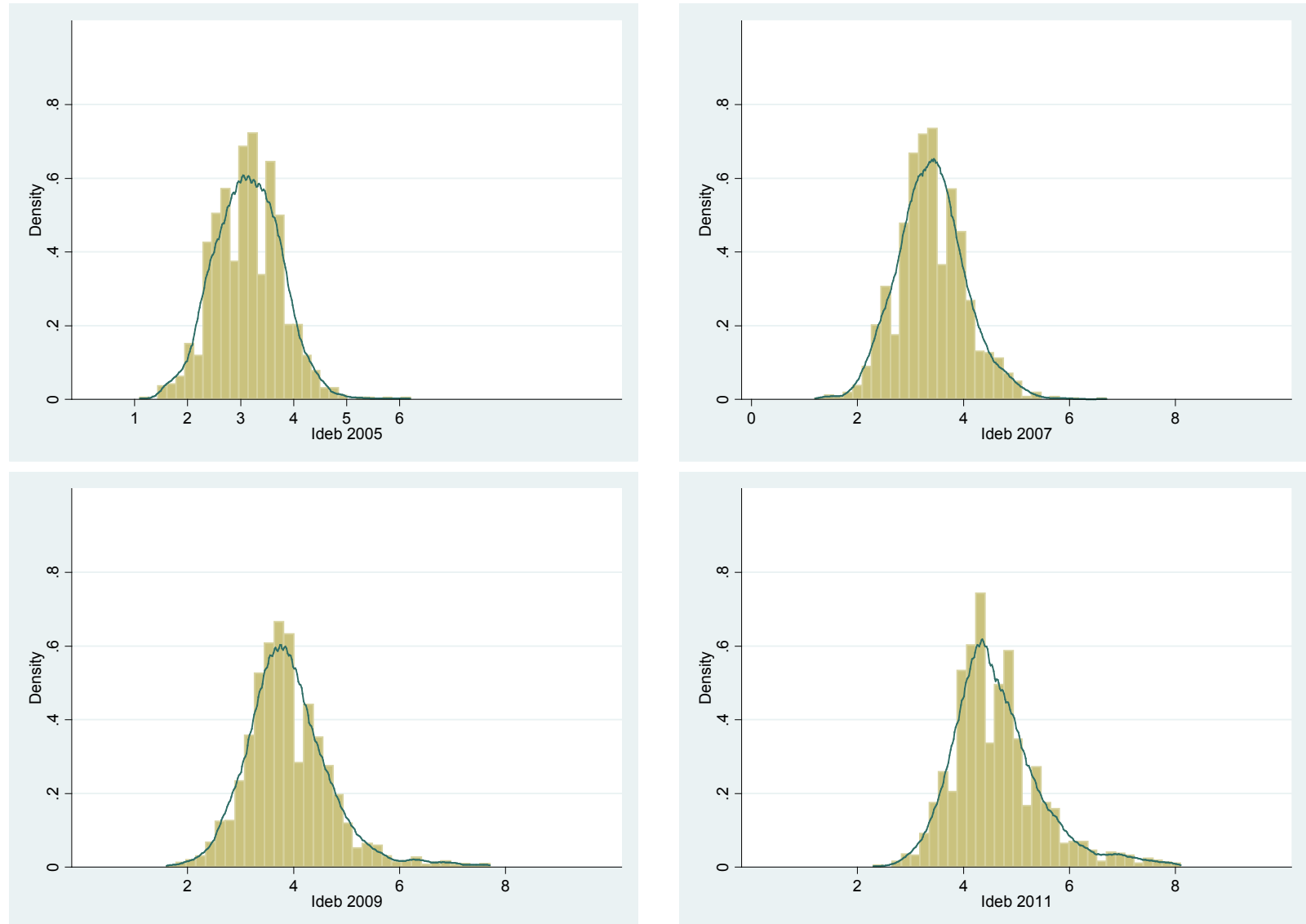

Figura 1. Histogramas e densidades de kernel do Ideb do EF1 das escolas por ano Fonte: Elaboração própria com dados do Inep.
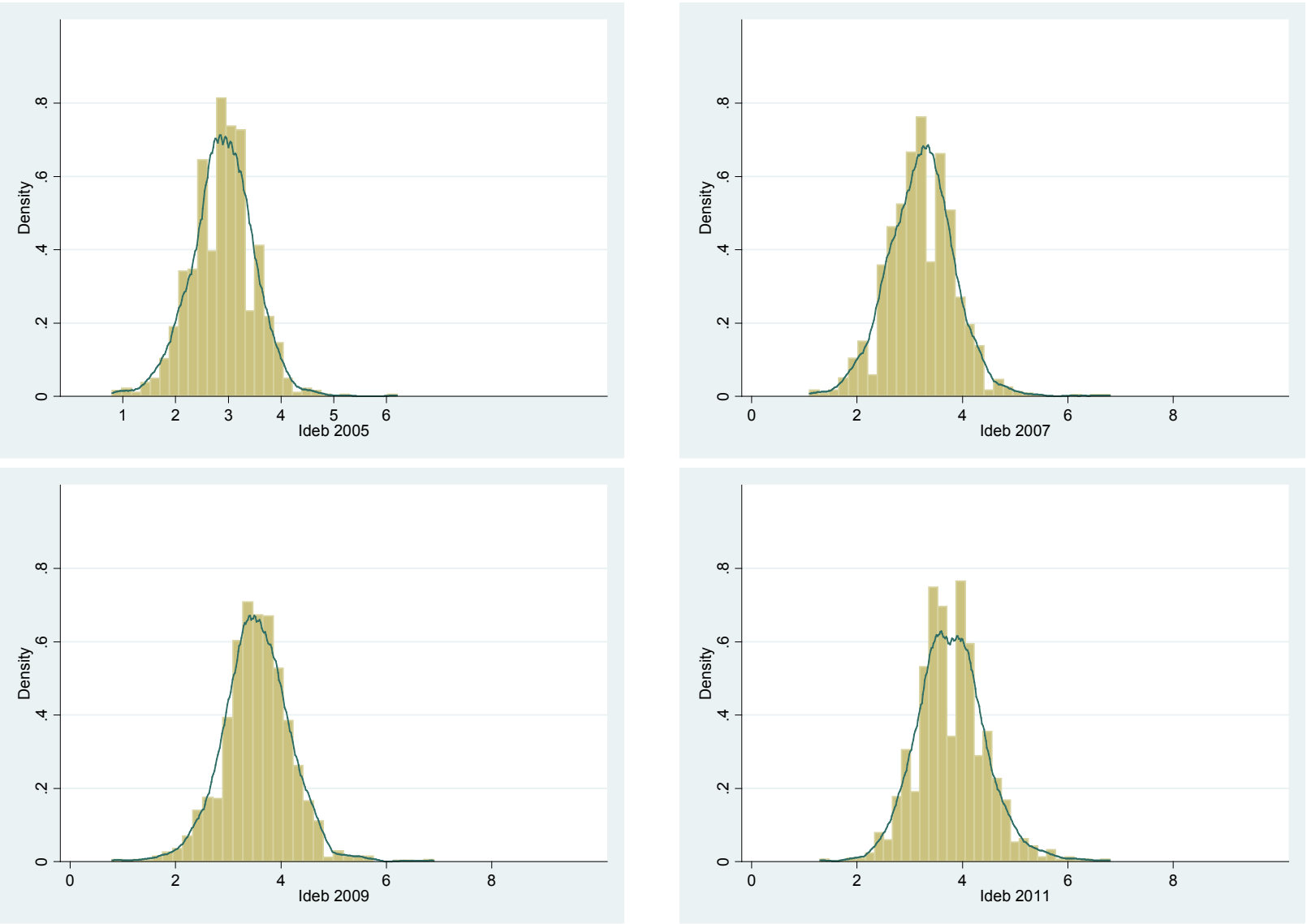

Figura 2. Histogramas e densidades de kernel do Ideb do EF2 das escolas por ano Fonte: Elaboração própria com dados do Inep. 
Tabela 5. Estatísticas descritivas das distribuições de Ideb no EF1

\begin{tabular}{c:ccccccc} 
Ano & Média & $\begin{array}{c}\text { Desvio } \\
\text { padrão }\end{array}$ & Mínimo & Máximo & Assimetria & Curtose \\
\hline 2005 & 3.1360 & 0.6286 & 1.1000 & 6.2000 & 0.1862 & 3.5529 \\
\hline 2007 & 3.3983 & 0.6505 & 1.2000 & 6.7000 & 0.3187 & 3.7670 \\
\hline 2009 & 3.9062 & 0.8051 & 1.6000 & 7.7000 & 0.9548 & 5.4299 \\
\hline 2011 & 4.6316 & 0.8454 & 2.3000 & 8.1000 & 1.0013 & 4.7367 \\
\hline & & & Município & & & \\
\hline 2005 & 3.0190 & 0.4726 & 1.5333 & 4.4000 & -0.2411 & 3.3048 \\
\hline 2007 & 3.3337 & 0.4951 & 1.8500 & 5.1000 & 0.3186 & 3.7706 \\
\hline 2009 & 3.8585 & 0.5605 & 2.4500 & 6.6462 & 1.1847 & 7.1734 \\
\hline 2011 & 4.6686 & 0.6262 & 3.0000 & 7.2171 & 0.9302 & 5.1743 \\
\hline & & & Crede & & & \\
\hline 2005 & 3.0449 & 0.2539 & 2.4538 & 3.4398 & -0.4668 & 2.5627 \\
\hline 2007 & 3.3448 & 0.2424 & 2.9780 & 3.7296 & -0.1325 & 1.7296 \\
\hline 2009 & 3.8418 & 0.2978 & 3.2732 & 4.6220 & 0.5987 & 3.9820 \\
\hline 2011 & 4.6198 & 0.3905 & 3.8915 & 5.5006 & 0.6126 & 3.1144 \\
\hline
\end{tabular}

Fonte: Elaboração própria com dados do Inep.

Tabela 6. Estatísticas descritivas das distribuições de Ideb no EF2

\begin{tabular}{lllll|l|l|l} 
Ano & Média & $\begin{array}{l}\text { Desvio } \\
\text { padrão }\end{array}$ & Mínimo & Máximo & Assimetria & Curtose \\
\hline 2005 & 2.8935 & 0.5962 & 0.8000 & 6.2000 & 0.0092 & 4.3419 \\
\hline 2007 & 3.2194 & 0.6378 & 1.1000 & 6.8000 & 0.2418 & 4.6521 \\
\hline 2009 & 3.5389 & 0.6477 & 0.8000 & 6.9000 & 0.1231 & 4.6899 \\
\hline 2011 & 3.7917 & 0.6592 & 1.3000 & 6.8000 & 0.3800 & 4.1604 \\
\hline 2005 & 2.9268 & 0.3990 & 1.5800 & 4.0000 & -0.0891 & 3.6011 \\
\hline 2007 & 3.2301 & 0.3940 & 2.1000 & 4.6000 & 0.2726 & 3.6828 \\
\hline 2009 & 3.5590 & 0.4281 & 2.4000 & 5.4400 & 1.0151 & 6.8540 \\
\hline 2011 & 3.8083 & 0.4342 & 2.8000 & 5.7333 & 0.7746 & 4.7005 \\
\hline & & & Crede & & & \\
\hline 2005 & 2.9206 & 0.1638 & 2.5920 & 3.1634 & -0.3091 & 1.9001 \\
\hline 2007 & 3.2381 & 0.1784 & 2.7827 & 3.4805 & -0.8136 & 3.1348 \\
\hline 2009 & 3.5215 & 0.1765 & 3.0977 & 3.7750 & -0.5693 & 2.9841 \\
\hline 2011 & 3.7780 & 0.2204 & 3.3743 & 4.2436 & 0.3998 & 2.6496
\end{tabular}

Fonte: Elaboração própria com dados do Inep. 
A tendência geral de alongamento da cauda à direita das densidades nos levou a investigar melhor o grupo de maior Ideb, com o intuito de responder às seguintes questões: escolas, municípios e Credes da cauda mais longa seriam os mesmos nos diferentes anos? Onde estariam localizadas as escolas desse grupo? Para responder tais perguntas verificamos a distribuição por quintis nos anos 2005, 2007 e 2009 das escolas que se encontravam no último quintil em 2011. A Figura 3 nos mostra que o grupo de escolas com Ideb entre os 20\% maiores em 2011 não é o mesmo ao longo do tempo. Em 2005, apenas $30 \%$ dessas escolas (existentes em 2005) estavam no último quintil; em 2007, esse percentual era de 40\%; e, em 2009, 60\%. Algo semelhante acontece no EF2.

EF1

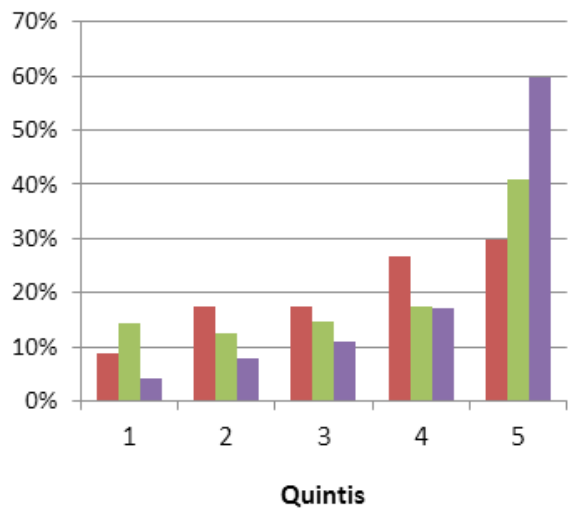

EF2

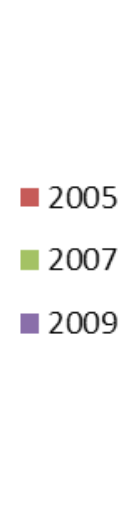

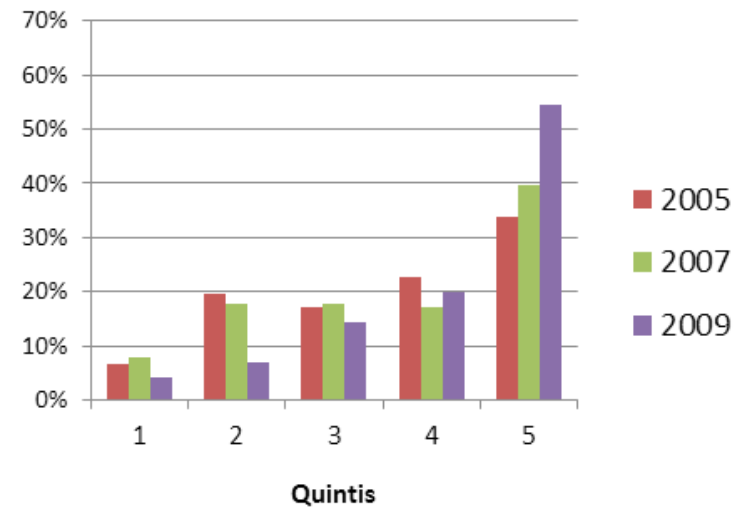

Figura 3: Distribuição das escolas do último quintil de Ideb em 2011 nos quintis dos anos anteriores, por etapa

Fonte: Elaboração própria com base em dados do Inep.

Apesar da relativa instabilidade do grupo de escolas de maior Ideb, identificamos um grupo que conseguiu se manter no último quintil da distribuição de forma consistente (que ocupou tal quintil em todos os anos que possuía Ideb). Após identificarmos esses estabelecimentos de ensino, calculamos sua proporção por município. Com base nisso, identificamos sete municípios cuja maioria (>50\%) das escolas de EF1 está neste grupo - Cruz, Forquilha, Groaíras, Jijoca de Jericoacoara, Mucambo, Pedra Branca e Sobral. No EF2, identificamos dois municípios - Cruz e Itaiçaba. Fizemos o mesmo exercício com os municípios e identificamos que, no EF1 e no EF2, não há Crede com a maioria de suas cidades no último quintil de forma consistente. $A$ Crede que mais concentra municípios de alto Ideb (cerca de 30\%), em ambas as etapas, é Acaraú. Por fim, checou-se se havia Credes de alto Ideb em todo 
o período, e no EF1, identificou-se Sobral, enquanto no EF2, Acaraú.

É interessante notar que, com exceção dos municípios de Pedra Branca e Itaiçaba, todos os outros cuja maioria das escolas possui alto Ideb consistentemente estão nas Credes de Sobral e Acaraú (ver Figura 4).

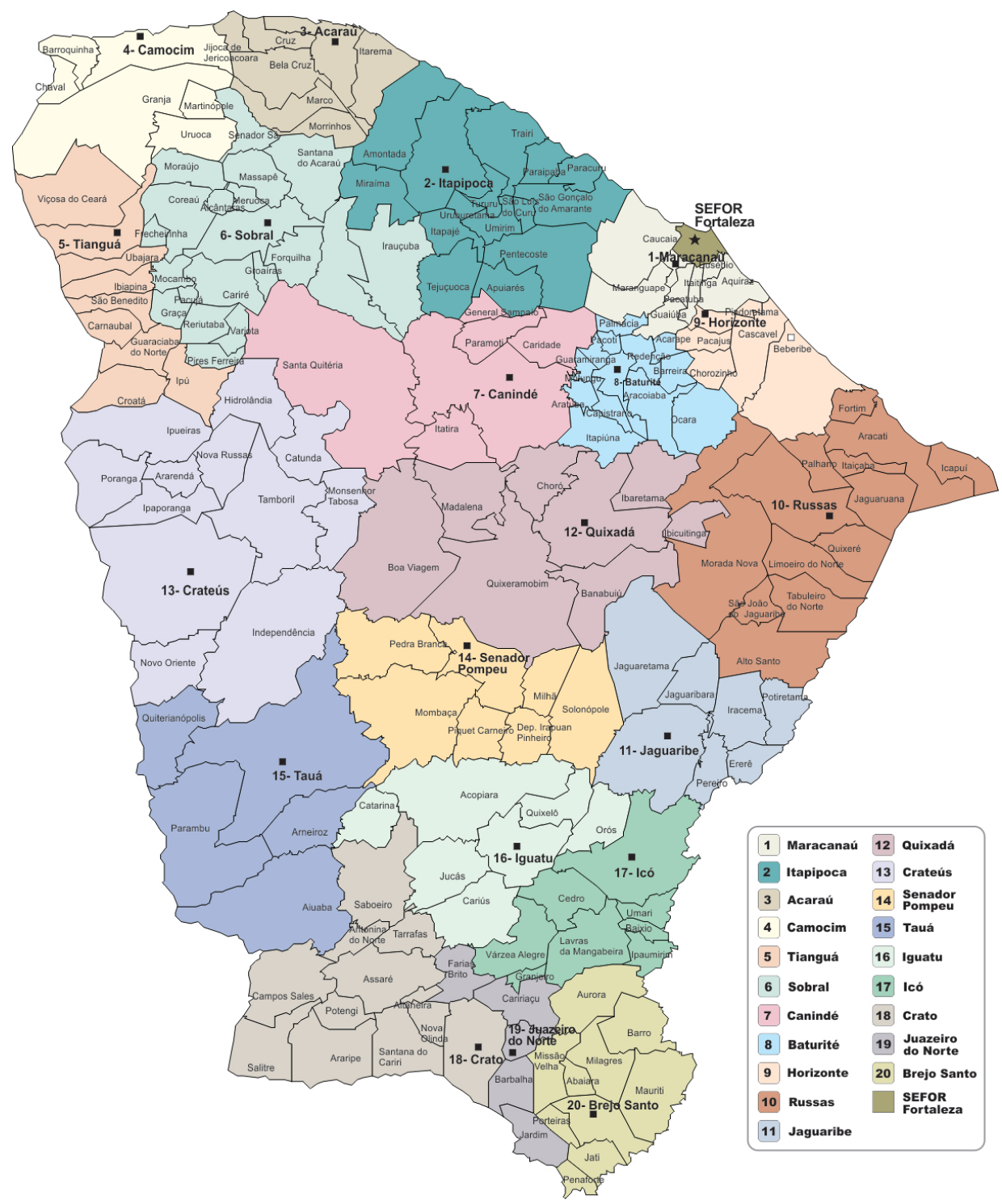

Figura 4 - Mapa do estado do Ceará com Credes

Fonte: Secretaria de Educação do Estado do Ceará.

\section{A EVOLUÇÃO DA EQUIDADE}

3.1 Modelos MULTINÍVEIS PARA A ANÁLISE dOS COMPONENTES DA VARIÂNCIA

Esta seção pretende analisar, a partir de modelos multiníveis, a proporção da variância total entre o Ideb das escolas explicada pela variância entre 
Credes e entre municípios. Serão utilizados dois modelos nulos (sem variáveis explicativas), para os anos de 2007 e 2011, a fim de comparar os componentes da variância de cada nível nos dois períodos, a partir da correlação intraclasse.

No caso estudado, observamos que há uma relação hierárquica entre os grupos: as escolas pertencem a um município que, por sua vez, pertence a uma Crede. As unidades do primeiro nível (escolas) foram agrupadas segundo as unidades do segundo nível (municípios), que por sua vez foram agrupadas segundo as variáveis do terceiro nível (Credes). Cada escola é representada pelo índice ${ }^{i}$, cada município pelo índice $j$ e cada Crede pelo índice $k$.

Assim temos que, no primeiro nível, o Ideb da escola ${ }^{i}$, de um município $i$, de uma Crede $k$, é representado por $Y_{i j k}$, sendo função da média do Ideb no

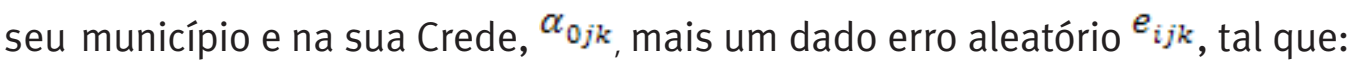

$$
Y_{i j k}=\alpha_{0 j k}+e_{i j k} \quad \text { nível } 1 \text { (escolas) }
$$

Os níveis do município e Credes são representados pelas seguintes equações:

$$
\begin{aligned}
& \alpha_{0 j k}=\beta_{00 k}+m_{0 j k} \quad \text { nível } 2 \text { (municípios) } \\
& \beta_{00 k}=\gamma_{000}+c_{00 k} \quad \text { nível } 3 \text { (Credes) }
\end{aligned}
$$

Onde $\beta_{00 k}$ é Ideb médio de escolas de uma determinada Crede; $\gamma_{000}$ é o Ideb médio geral das escolas; $m_{0 j k}$ é um efeito não observável do município; e $c_{00 k}$ é um efeito não observável da Crede.

A partir da variância dos efeitos aleatórios, $\operatorname{Var}\left(e_{i j k}\right)=\sigma_{e}^{2}, \operatorname{Var}\left(m_{0 j k}\right)=\sigma_{m}^{2}$ e $\operatorname{Var}\left(c_{00 k}\right)=\sigma_{c}^{2}$, obtemos as correlações intraclasses, que mostram a proporção da variância atribuída a cada nível:

$\begin{array}{ll}\frac{\sigma_{e}^{2}}{\sigma_{e}^{2}+\sigma_{m}^{2}+\sigma_{c}^{2}} & \text { nível } 1 \text { (escolas) } \\ \frac{\sigma_{m}^{2}}{\sigma_{e}^{2}+\sigma_{m}^{2}+\sigma_{c}^{2}} & \text { nível } 2 \text { (municípios) } \\ \frac{\sigma_{c}^{2}}{\sigma_{e}^{2}+\sigma_{m}^{2}+\sigma_{c}^{2}} & \text { nível } 3 \text { (Credes) }\end{array}$


A Tabela 7 mostra o componente da variância e a proporção da variância explicada (correlação intraclasse) por cada nível, para os anos de 2007 e 2011 no EF1, calculadas através do software Stata/SE 10.1:

Tabela 7. Modelo multinível nulo com níveis de Crede, município e Escola - EF1

\begin{tabular}{|c|c|c|c|c|c|c|c|c|}
\hline \multirow{3}{*}{$\begin{array}{l}\text { Níveis } \\
\text { Crede }\end{array}$} & \multicolumn{4}{|c|}{2007} & \multicolumn{4}{|c|}{2011} \\
\hline & $\begin{array}{c}\text { Variância } \\
\text { dos } \\
\text { efeitos } \\
\text { aleatórios }\end{array}$ & $\begin{array}{r}\text { Inter } \\
\text { confia } \\
9\end{array}$ & $\begin{array}{l}\text { alo de } \\
\text { nça de } \\
\%\end{array}$ & $\begin{array}{c}\text { Proporção } \\
\text { da variância } \\
\text { total }\end{array}$ & $\begin{array}{c}\text { Variância } \\
\text { dos efeitos } \\
\text { aleatórios }\end{array}$ & $\begin{array}{r}\text { Interv } \\
\text { confia } \\
9\end{array}$ & $\begin{array}{l}\text { alo de } \\
\text { nça de } \\
\%\end{array}$ & $\begin{array}{c}\text { Proporção } \\
\text { da } \\
\text { variância } \\
\text { total }\end{array}$ \\
\hline & 0,0162 & 0,0031 & 0,0842 & $3,69 \%$ & 0,0800 & 0,0332 & 0,1932 & $11,51 \%$ \\
\hline Município & 0,1406 & 0,1024 & 0,1930 & $31,93 \%$ & 0,2475 & 0,1903 & 0,3219 & $35,60 \%$ \\
\hline Escola & 0,2835 & 0,2628 & 0,3057 & $64,38 \%$ & 0,3677 & 0,3453 & 0,3916 & $52,89 \%$ \\
\hline Soma & 0,4403 & - & - & $100,00 \%$ & 0,6953 & - & - & $100,00 \%$ \\
\hline
\end{tabular}

Fonte: Elaborada pelos autores.

Nota: Em 2007 são 1.512 escolas; em 2011 são 2.114.

Dois resultados chamam a atenção na Tabela 7 - o primeiro é o fato de as variáveis ligadas ao município explicarem parcela considerável da variação do Ideb entre escolas em ambos os anos. 0 segundo diz respeito à redução da importância de variáveis do nível escolar e ao crescimento do poder explicativo do nível de Crede, visto que a proporção da variância total devida ao município pouco mudou. Ambos os resultados fazem sentido dentro do contexto cearense, que tem alta taxa de municipalização e onde o governo estadual é indutor de políticas para a primeira etapa do EF.

Nas últimas duas décadas, o governo do estado do Ceará vem apostando em uma política do tipo "descentralização orquestrada" dos anos iniciais do ensino fundamental (PADILHA; BATISTA, 2013). Nesse modelo, os municípios assumem a responsabilidade pelo ensino, mas o fazem em colaboração com o estado, que apoia a implementação das políticas ${ }^{10}$. Em 2007, foi universalizado no estado o Programa de Alfabetização na Idade Certa (Paic) ${ }^{11}$, que começou em 2004 por iniciativa da sociedade civil. Esse programa é focado no EF1 e tem sua gestão compartilhada pelo governo estadual.

Como pode ser observado na Tabela 8, no EF2, a parcela da variabilidade dos Idebs das escolas explicada pelas Credes manteve-se relativamente estável, a parcela de poder explicativo no nível das escolas se reduziu e a parcela

10 Em 2011, no estado do Ceará como um todo, 79,87\% da matrícula do EF 1 era municipal, 0,73\% estadual e 19,40\% particular; no EF2, 72,60\% era municipal, $12,58 \%$ estadual e $14,74 \%$ particular (Censo Escolar).

11 Para detalhes do Paic, ver Seduc e Unicef (2012). 
dos municípios se elevou. Em relação ao EF1, vemos que os níveis mais elevados, de município e Crede, explicam menos os resultados das escolas no EF2. Esses resultados sugerem que as políticas educacionais do âmbito da descentralização orquestrada podem ter um peso maior sobre os resultados do Ideb no EF1.

Tabela 8. Modelo multinível nulo com níveis de Crede, município e Escola - EF2

\begin{tabular}{|c|c|c|c|c|c|c|c|c|}
\hline \multirow[b]{2}{*}{ Níveis } & \multicolumn{4}{|c|}{2007} & \multicolumn{4}{|c|}{2011} \\
\hline & $\begin{array}{c}\text { Variância } \\
\text { dos } \\
\text { efeitos }\end{array}$ & $\begin{array}{l}\text { Inter } \\
\text { confian }\end{array}$ & $\begin{array}{l}\text { alo de } \\
\text { de } 95 \%\end{array}$ & $\begin{array}{c}\text { Proporção } \\
\text { da } \\
\text { variância }\end{array}$ & $\begin{array}{c}\text { Variância } \\
\text { dos } \\
\text { efeitos }\end{array}$ & $\begin{array}{r}\text { Inter } \\
\text { confianc }\end{array}$ & $\begin{array}{l}\text { lo de } \\
\text { de } 95 \%\end{array}$ & $\begin{array}{l}\text { Proporção } \\
\text { da } \\
\text { variância }\end{array}$ \\
\hline Crede & 0,0119 & 0,0030 & 0,0473 & $2,95 \%$ & 0,0177 & 0,0050 & 0,0633 & $3,96 \%$ \\
\hline Município & 0,0483 & 0,0288 & 0,0811 & $11,94 \%$ & 0,1048 & 0,0757 & 0,1451 & $23,41 \%$ \\
\hline Escola & 0,3443 & 0,3175 & 0,3734 & $85,11 \%$ & 0,3251 & 0,3033 & 0,3484 & $72,63 \%$ \\
\hline Soma & 0,4046 & - & - & $100,00 \%$ & 0,4476 & - & - & $100,00 \%$ \\
\hline
\end{tabular}

Fonte: Elaborada pelos autores.

Nota: Em 2007 são 1.307 escolas; em 2011 são 1.773.

\subsection{O IDEB E SUA EVOLUÇÃO: UMA ANÁLISE DA EQUIDADE A PARTIR DO NSE DAS ESCOLAS E DOS GRUPOS DE MUNICÍPIOS}

Tendo em vista o conceito de equidade adotado neste trabalho, uma melhoria da igualdade do sistema educacional é verificada quando a influência do NSE sobre os resultados escolares se reduz. Em outras palavras, quando alunos de menor NSE conseguem alcançar resultados tão bons quanto dos alunos de alto NSE. Dessa forma, para verificar se houve aumento da equidade no Ceará, vamos estimar regressões para explicar a variação do Ideb no tempo, controlando pelo NSE dos alunos e dos municípios. Cabe lembrar que estamos usando a classificação do IBGE (2007) como medida de NSE das cidades e um indicador de NSE das escolas construído com base no Critério Brasil usando dados da Prova Brasil 2007 e 2011.

Foram estimados modelos multiníveis visando verificar: (i) o peso do NSE das escolas no resultado do Ideb; (ii) a evolução desse peso entre 2007 e 2011; e (iii) se o NSE influencia o Ideb das escolas de maneira diferente nos grupos de municípios analisados.

No nível das escolas, como variável explicativa, foi utilizado o seu NSE. Adicionalmente, para testar a variação do Ideb entre os anos de 2007 e 2011, foi acrescentada ao modelo uma variável binária para o ano de 2011, assim 
como uma interação entre o ano e o NSE. Para verificar se o NSE influencia as escolas diferentemente nos grupos de municípios, fizemos os coeficientes do NSE dependerem de variáveis binárias que indicam o grupo do município, e para investigar se tal influência mudou no tempo, incluímos interações do NSE de escolas e municípios com tempo. Para uma descrição mais detalhada das variáveis explicativas, ver Tabela 9. As equações abaixo apresentam a especificação dos modelos, que contém dois níveis.

Nível 1

$\begin{aligned} \ln \left(\text { Ideb }_{i j}\right)= & \alpha_{0}+\alpha_{1 j} \text { classeAB }_{i j}+\alpha_{2 j} \text { classe }_{i j}+\alpha_{3 j} \text { classe }_{i j}+\alpha_{4} \text { ano } 11+\alpha_{5} \text { ano } 11 \\ & \times \text { classeAB }_{i j}+\alpha_{6} \text { ano } 11 \times \text { classe }_{i j}+\alpha_{7} \text { ano } 11 \times \text { classe } D_{i j}+e_{i j}\end{aligned}$

Nível 2

$\alpha_{0}=\beta_{0}+\beta_{1} \operatorname{cen} 1+\beta_{2} \operatorname{cen} 2+m_{j 0}$

$\alpha_{h j}=\beta_{0 h}+\beta_{1 h} \operatorname{cen} 1_{j}+\beta_{2 h} \operatorname{cen} 2_{j}+m_{j h}, h=1,2,3,5,6,7$

Tomamos o logaritmo natural da variável dependente para flexibilizar o modelo. Quando se usa o Ideb no nível, assume-se que quando uma covariada muda, o efeito sobre a dependente é sempre o mesmo em termos absolutos. Quando usamos o logaritmo do Ideb, assume-se que quando há uma variação em alguma variável explicativa, a dependente varia sempre da mesma forma em termos percentuais, de forma que $\Delta \%$ Ideb $=100 \times$ efeito marginal da variável $x \times \Delta x$, sendo $x$ qualquer covariada do modelo.

Como nos modelos nulos as variâncias associadas aos três níveis eram estatisticamente diferentes de zero, nós também estimamos modelos com três níveis hierárquicos (não reportados). Porém, esses modelos apresentaram resultados muito parecidos com os modelos de dois níveis, tanto em termos de tamanho quanto de significância dos coeficientes, e optamos por usar 0 modelo com dois níveis ${ }^{12}$. $O$ resultado do modelo para o EF1 pode ser visto na Tabela 10.

12 Tal resultado faz sentido visto que o percentual da variância devido ao nível da Crede é baixo nas duas etapas do EF. 
Tabela 9. Descrição das variáveis usadas nas regressões

\begin{tabular}{|c|c|c|}
\hline \multirow{3}{*}{$\begin{array}{l}\text { Variável } \\
\text { Dependente: } \\
\text { Qualidade do } \\
\text { ensino }\end{array}$} & Nome & Descrição \\
\hline & $\ln \left(I d e b_{i j}\right)$ & $\begin{array}{l}\text { Logaritmo natural do Ideb da escola } i \text {, que se localiza } \\
\text { no município } i \text {. }\end{array}$ \\
\hline & classe $A B_{i j}$ & $\begin{array}{l}\text { Percentual de alunos das classes econômicas A e B na } \\
\text { escola }{ }^{i} \text {. }\end{array}$ \\
\hline \multirow{2}{*}{$\begin{array}{l}\text { Nível } \\
\text { socioeconômico } \\
\text { da escola }\end{array}$} & classe $_{i j}$ & $\begin{array}{l}\text { Percentual de alunos da classe econômica C na escola } \\
\text { i. }\end{array}$ \\
\hline & classe $D_{i j}$ & $\begin{array}{l}\text { Percentual de alunos da classe econômica D na escola } \\
\text { i. } \\
\text { Omitida: percentual de alunos da classe E. }\end{array}$ \\
\hline Tempo & ano11 & $\begin{array}{l}\text { Variável binária que assume valor } 1 \text { quando o ano é } \\
2011 . \\
\text { Omitida: ano de } 2007 .\end{array}$ \\
\hline \multirow{4}{*}{$\begin{array}{l}\text { Interações do NSE } \\
\text { das escolas com o } \\
\text { tempo }\end{array}$} & ano $11 \times$ classeA $B_{i j}$ & Multiplicação das variáveis ano $11 \mathrm{e}^{\text {classe } A B_{i j}}$ \\
\hline & ano $11 \times$ classe $C_{i j}$ & Multiplicação das variáveis ano11 $\mathrm{e}^{\text {classe } C_{i j}}$. \\
\hline & ano $11 \times$ classe $D_{i j}$ & Multiplicação das variáveis ano $11 \mathrm{e}^{\text {classe } D_{i j}}$. \\
\hline & $\operatorname{cen} 1_{j}$ & $\begin{array}{l}\text { Variável binária que assume valor } 1 \text { quando o } \\
\text { município } i \text { é Fortaleza (metrópole). }\end{array}$ \\
\hline \multirow[t]{2}{*}{$\begin{array}{l}\text { Nível } \\
\text { socioeconômico } \\
\text { do município }\end{array}$} & $\operatorname{cen} 2_{j}$ & $\begin{array}{l}\text { Variável binária que assume valor } 1 \text { quando o } \\
\text { município } i \text { é do grupo Capitais Regionais e Centros } \\
\text { Sub-regionais. } \\
\text { Omitida: grupo Centros de Zona e Centros Locais. }\end{array}$ \\
\hline & $\operatorname{cen} 1_{j} \times$ classe $A B_{i j}$ & Multiplicação das variáveis ${ }^{\operatorname{cen} 1} 1_{j} \mathrm{e}^{\text {classe } A B_{i j}}$ \\
\hline \multirow{6}{*}{$\begin{array}{l}\text { Interações do NSE } \\
\text { dos municípios } \\
\text { com o NSE das } \\
\text { escolas }\end{array}$} & $\operatorname{cen} 2_{j} \times$ classe $A B_{i j}$ & Multiplicação das variáveis ${ }^{\operatorname{cen} 2_{j}} \mathrm{e}^{\text {classeA } A B_{i j}}$. \\
\hline & $\operatorname{cen} 1_{j} \times$ classe $C_{i j}$ & Multiplicação das variáveis ${ }^{\operatorname{cen} 1} 1_{j} \mathrm{e}^{\text {classe } C_{i j}}$. \\
\hline & $\operatorname{cen} 2_{j} \times$ classe $C_{i j}$ & Multiplicação das variáveis ${ }^{c e n} 2_{j} \mathrm{e}^{\text {classe }} C_{i j}$. \\
\hline & cen $1_{j} \times$ classe $D_{i j}$ & Multiplicação das variáveis ${ }^{\operatorname{con} 1} 1_{j} \mathrm{e}^{\text {classe } D_{i j}}$ \\
\hline & $\operatorname{cen} 2_{j} \times$ classe $D_{i j}$ & Multiplicação das variáveis ${ }^{\operatorname{cen} 2} 2_{j} \mathrm{e}^{\text {classe } D_{i j}}$ \\
\hline & ano $11 \times \operatorname{cen} 1_{j} \times$ classe $A B_{i j}$ & 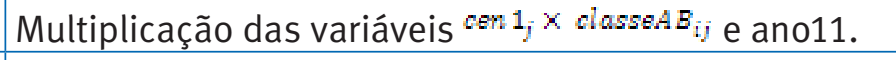 \\
\hline \multirow{5}{*}{$\begin{array}{l}\text { Interações do NSE } \\
\text { dos municípios } \\
\text { com o NSE das } \\
\text { escolas e com o } \\
\text { tempo }\end{array}$} & ano $11 \times$ cen $2_{j} \times$ classe $A B_{i j}$ & 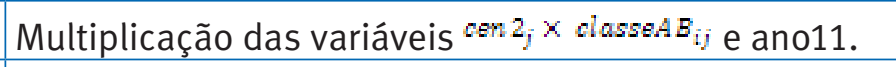 \\
\hline & ano $11 \times \operatorname{cen} 1_{j} \times$ classe $C_{i j}$ & Multiplicação das variáveis ${ }^{\operatorname{cen} 1} 1_{j} \times$ classe $_{i j}$ e ano11. \\
\hline & ano $11 \times \operatorname{cen} 2_{j} \times$ classe $_{i j}$ & Multiplicação das variáveis ${ }^{\text {cen } 2}{ }_{j} \times$ classe $C_{i j}$ e ano11. \\
\hline & ano $11 \times$ cen $1_{j} \times$ classe $D_{i j}$ & Multiplicação das variáveis ${ }^{c e n} 1_{j} \times$ classe $D_{i j}$ e ano11. \\
\hline & ano $11 \times \operatorname{cen} 2_{j} \times$ classe $D_{i j}$ & Multiplicação das variáveis ${ }^{c e n} 2_{j} \times$ classe $D_{i j}$ e ano11. \\
\hline
\end{tabular}

O efeito da variável Classe $A B$, por exemplo, no Ideb é dado pela expressão: $\beta_{01}+\beta_{11}$ cen $1_{j}+\beta_{21}$ cen $2_{j}+\beta_{05}$ ano $11+\beta_{15}$ ano $11 \times$ cen $1+\beta_{25}$ ano $11 \times$ cen 2

. Ou seja, o efeito dessa variável depende do grupo de município ao qual pertence a escola e do ano, de forma que $\beta_{01}$ informa a diferença de Ideb (em percentual) entre escolas com um ponto percentual (p.p.) a mais de alunos 
das classes A e B (e, portanto, com 1 p.p. a menos de alunos na classe E), frente a escolas em municípios classificados como centros de zona e centros locais em 2007; $\beta_{11}$ dá a variação percentual do Ideb entre escolas localizadas em cidades do grupo capitais regionais e centros sub-regionais, frente a escolas do grupo de referência em 2007; $\beta_{21}$ é análogo a $\beta_{11}$, considerando a metrópole; $\beta_{05}$ informa a diferença em termos percentuais de Ideb entre 2011 e 2007, dada uma elevação de 1 p.p. em ClasseAB (tal coeficiente informa se o efeito da variável se enfraqueceu ou não de 2007 a 2011). Os coeficientes $\beta_{15}$ e $\beta_{25}$ indicam se o peso do NSE em determinado grupo de município se enfraqueceu ou não ao longo do tempo. O efeito das outras variáveis de NSE (ClasseC $\mathrm{e}^{\text {Classe D }) ~ e ́ ~ o b t i d o ~ d e ~ m a n e i r a ~ a n a ́ l o g a . ~ O ~ c o e f i c i e n t e ~} \alpha_{4}$ de ano11 expressa a variação do Ideb no tempo e capta o efeito de acontecimentos macro que afetaram todas as escolas do estado.

Tabela 10. Modelo multinível para o EF1

\begin{tabular}{|c|c|c|c|c|c|}
\hline $\begin{array}{l}\text { Parâmet- } \\
\text { ro }\end{array}$ & Dependente: logaritmo do Ideb & Coeficien & & Erro padrão & $\mathrm{p}$-valor \\
\hline$\beta_{1}$ & cen1 & -0.2731 & $\star \star \star$ & 0.0702 & 0.0000 \\
\hline$\beta_{2}$ & cen 2 & 0.0816 & & 0.3047 & 0.7890 \\
\hline$\beta_{n 1}$ & classeAB & 0.8825 & *** & 0.1614 & 0.0000 \\
\hline$\beta_{n 2}$ & classeC & 0.4874 & $\star \star \star$ & 0.0788 & 0.0000 \\
\hline$\beta_{n z}$ & classeD & 0.1360 & & 0.1117 & 0.2230 \\
\hline$a_{4}$ & ano11 & 0.3794 & $\star \star \star$ & 0.0850 & 0.0000 \\
\hline$\beta_{n 5}$ & ano11_classeAB & -0.3630 & ** & 0.1640 & 0.0270 \\
\hline$\beta_{n k}$ & ano11_classeC & -0.1625 & * & 0.0841 & 0.0530 \\
\hline$\beta_{n 7}$ & ano11_classeD & 0.0078 & & 0.1252 & 0.9500 \\
\hline$\beta_{11}$ & cen1_classeAB & 0.3750 & ** & 0.1576 & 0.0170 \\
\hline$\beta_{21}$ & cen2_classeAB & -0.0557 & & 0.4000 & 0.8890 \\
\hline$\beta_{12}$ & cen1_classeC & 0.1030 & & 0.0731 & 0.1590 \\
\hline$\beta_{22}$ & cen2_classeC & -0.0112 & & 0.3245 & 0.9720 \\
\hline$\beta_{12}$ & cen1_classeD & 0.2881 & $\star \star \star$ & 0.1027 & 0.0050 \\
\hline$\beta_{23}$ & cen2_classeD & 0.0051 & & 0.3534 & 0.9880 \\
\hline$\beta_{15}$ & ano11_cen1_classeAB & -0.0254 & & 0.1313 & 0.8460 \\
\hline$\beta_{25}$ & ano11_cen2_classeAB & -0.0046 & & 0.0474 & 0.9230 \\
\hline$\beta_{1 k}$ & ano11_cen1_classeC & -0.3206 & $\star \star \star$ & 0.0538 & 0.0000 \\
\hline$\beta_{2 \hbar}$ & ano11_cen2_classeC & 0.0640 & & 0.2867 & 0.8230 \\
\hline$\beta_{17}$ & ano11_cen1_classeD & -0.0718 & & 0.1220 & 0.5560 \\
\hline$\beta_{27}$ & ano11_cen2_classeD & -0.0220 & & 0.1924 & 0.9090 \\
\hline$\beta_{\mathrm{n}}$ & constante & 0.8745 & $\star \star \star$ & 0.0776 & 0.0000 \\
\hline- & Observações & 3626 & & Log-veross. & 1653.6058 \\
\hline- & Rho & 0.3454 & & E. p. rho & 0.0301 \\
\hline
\end{tabular}

*** p-valor<0,01; ** p-valor<0,05; * p-valor<0,1.

Erro padrão calculado por bootstrap.

Fonte: Elaborada pelos autores. 
Observa-se, na Tabela 11, que o NSE influencia o Ideb, pois escolas com maior percentual de alunos das classes A, B e C apresentam resultados melhores do que escolas com mais alunos da classe E. Contudo, o peso do NSE se reduziu de 2007 para 2011, fato que evidencia uma melhora de equidade no EF1. Os resultados mudam um pouco para a metrópole, pois, dado que as escolas se localizam em Fortaleza, a diferença de Ideb entre estabelecimentos com alunos de maior NSE, especificamente das classes A, B e D, e de menor NSE (classe E) é maior; mas a diferença de Ideb entre escolas com mais alunos da classe $\mathrm{C}$ e com mais alunos da classe $\mathrm{E}$ se reduz no tempo mais intensamente.

Para entendermos a diferença dos resultados de Fortaleza cabe citar dois fatos: conforme pode servisto na Tabela 4, Fortaleza concentra mais alunos de maior NSE; e as escolas de Fortaleza apresentam maior homogeneidade quanto ao NSE de seus alunos, relativamente aos municípios de centralidades mais baixas (ver Tabela 12). Isso sugere que a concentração dos alunos de classes mais altas em escolas específicas não favorece a equidade educacional.

Na Tabela 11 temos os resultados para o EF2. Nessa etapa, houve apenas um leve ganho de equidade nos municípios classificados como capitais regionais e centros sub-regionais. Nos demais grupos, não se observa aumento de equidade, pois o peso do NSE não mudou ao longo do tempo. Novamente Fortaleza se diferencia dos demais municípios, onde o efeito de classe $A B$ e classeC é maior e onde a distância entre as classes C e E aumenta de 2007 a 2011.

Em suma, com base nos modelos estimados nesta seção, verifica-se que no EF1 houve ganho de equidade, pois a influência do NSE diminuiu no período considerado. Já no EF2 só foram observadas melhorias nos municípios de centralidade intermediária.

Tabela 11. Modelo multinível para o EF2

\begin{tabular}{|c|c|c|c|c|c|}
\hline Parâmetro & Dependente: logaritmo do Ideb & Coefici & nte & $\begin{array}{l}\text { Erro } \\
\text { padrã }\end{array}$ & $p$-valor \\
\hline$\beta_{1}$ & cen1 & -1.1066 & 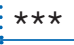 & 0.0701 & 0.0000 \\
\hline$\beta_{2}$ & cen2 & 0.0704 & & 0.3203 & 0.8260 \\
\hline$\beta_{n 1}$ & classe $A B$ & 0.7515 & 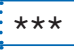 & 0.1162 & 0.0000 \\
\hline$\beta_{n 2}$ & classeC & 0.1538 & * & 0.0850 & 0.0700 \\
\hline$\beta_{n z}$ & classeD & -0.1078 & & 0.1056 & 0.3080 \\
\hline$a_{4}$ & ano11 & 0.0212 & & 0.1034 & 0.8370 \\
\hline$\beta_{n 5}$ & ano11_classe $A B$ & -0.0576 & & 0.1554 & 0.7110 \\
\hline$\beta_{n k}$ & ano11_classeC & 0.0918 & & 0.1101 & 0.4050 \\
\hline$\beta_{n 7}$ & ano11_classeD & 0.1716 & & 0.1282 & 0.1810 \\
\hline$\beta_{11}$ & cen1_classeAB & 1.0764 & 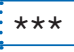 & 0.1111 & 0.0000 \\
\hline$\beta_{21}$ & cen2 classe $A B$ & 0.2502 & & 0.4361 & 0.5660 \\
\hline$\beta_{12}$ & cen1_classeC & 1.1618 & 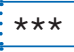 & 0.0757 & 0.0000 \\
\hline$\beta_{22}$ & cen2 classeC & -0.1828 & & 0.3355 & 0.5860 \\
\hline
\end{tabular}




\begin{tabular}{|c|c|c|c|c|c|}
\hline Parâmetro & Dependente: logaritmo do Ideb & \multicolumn{2}{|c|}{ Coeficiente } & $\begin{array}{c}\text { Erro } \\
\text { padrão }\end{array}$ & p-valor \\
\hline$\beta_{13}$ & cen1_classeD & 0.0940 & & 0.0934 & 0.3140 \\
\hline$\beta_{23}$ & cen2 classeD & -0.1479 & & 0.4123 & 0.7200 \\
\hline$\beta_{15}$ & ano11_cen1_classeAB & 0.1063 & & 0.1096 & 0.3320 \\
\hline$\beta_{25}$ & ano11_cen2_classeAB & -0.2199 & $\star \star \star$ & 0.0281 & 0.0000 \\
\hline$\beta_{1 k}$ & ano11_cen1_classeC & 0.6717 & $\star \star \star$ & 0.0370 & 0.0000 \\
\hline$\beta_{2 k}$ & ano11_cen2_classeC & -0.2323 & & 0.3123 & 0.4570 \\
\hline$\beta_{17}$ & ano11 cen1 classeD & 0.0286 & & 0.1189 & 0.8100 \\
\hline$\beta_{27}$ & ano11_cen2_classeD & 0.1350 & & 0.2783 & 0.6280 \\
\hline$\beta_{n}$ & constante & 1.0767 & 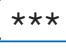 & 0.0799 & 0.0000 \\
\hline- & Observações & 3080 & & Log-veross. & 1185.9443 \\
\hline- & rho & 0.2289 & & E.p.rho & 0.0322 \\
\hline
\end{tabular}

*** p-valor<0,01; ** p-valor<0,05; * $p$-valor<0,1.

Erro padrão calculado por bootstrap.

Fonte: Elaborada pelos autores.

Tabela 12. Características da distribuição de alunos por classe nas escolas e por grupo de municípios

\begin{tabular}{|c|c|c|c|c|c|c|}
\hline \multirow[b]{2}{*}{$\begin{array}{l}\% \text { de escolas } \\
\text { com mais de: }\end{array}$} & \multicolumn{3}{|c|}{2011} & \multicolumn{3}{|c|}{2007} \\
\hline & Metrópole & $\begin{array}{l}\text { Capitais Regionais } \\
\text { e Centros Sub- } \\
\text { regionais }\end{array}$ & $\begin{array}{l}\text { Centros } \\
\text { de Zona } \\
\text { e Centros } \\
\text { Locais }\end{array}$ & $\begin{array}{l}\text { Metró- } \\
\text { pole }\end{array}$ & $\begin{array}{l}\text { Capitais Regionais } \\
\text { e Centros Sub- } \\
\text { regionais }\end{array}$ & $\begin{array}{l}\text { Centros } \\
\text { de Zona } \\
\text { e Centros } \\
\text { Locais }\end{array}$ \\
\hline $\begin{array}{c}50 \% \text { dos alu- } \\
\text { nos das classes } \\
\text { A, B ou C }\end{array}$ & $100,00 \%$ & $92,14 \%$ & $82,36 \%$ & $97,70 \%$ & $79,04 \%$ & $58,28 \%$ \\
\hline $\begin{array}{c}50 \% \text { dos alu- } \\
\text { nos das classes } \\
\text { D ou E }\end{array}$ & $0,00 \%$ & $7,86 \%$ & $17,64 \%$ & $2,30 \%$ & $20,96 \%$ & $41,72 \%$ \\
\hline $\begin{array}{c}25 \% \text { dos alu- } \\
\text { nos das classes } \\
\text { A ou B }\end{array}$ & $16,67 \%$ & $3,49 \%$ & $2,31 \%$ & $6,90 \%$ & $2,99 \%$ & $1,58 \%$ \\
\hline $\begin{array}{l}25 \% \text { dos alu- } \\
\text { nos da classe } E\end{array}$ & $0,00 \%$ & $0,87 \%$ & $1,29 \%$ & $0,29 \%$ & $2,40 \%$ & $7,42 \%$ \\
\hline $\begin{array}{l}50 \% \text { dos alu- } \\
\text { nos da classe C }\end{array}$ & $98,33 \%$ & $83,84 \%$ & $73,00 \%$ & $87,93 \%$ & $64,67 \%$ & $41,24 \%$ \\
\hline $\begin{array}{l}50 \% \text { dos alu- } \\
\text { nos da classe D }\end{array}$ & $0,00 \%$ & $0,87 \%$ & $5,04 \%$ & $0,00 \%$ & $5,39 \%$ & $8,93 \%$ \\
\hline
\end{tabular}

Fonte: Elaborada pelos autores com base em dados do Inep e IBGE.

\section{ANÁlise dA EVOLUÇÃO do IDEB E SEUS COMPONENTES NAS ESCOLAS POR GRUPOS DE MUNICÍPIOS}

O Ideb combina informações de proficiência e de fluxo escolar. Mais especificamente, o indicador combina a nota dos alunos na Prova Brasil e Saeb nas disciplinas de matemática e língua portuguesa e também a taxa de 
aprovação ${ }^{13}$. Por isso, cabe questionarmos se houve melhorias nesses três componentes e qual deles explicaria a maior parcela do crescimento do Ideb.

Os dados apresentados nas tabelas 13 e 14 tratam dos subindicadores (indicador de rendimento e nota média padronizada) do Ideb e suas variações a partir das subdivisões regionais, tendo em vista o critério das regiões de influência IBGE 2007. É importante ressaltar que o nível socioeconômico médio segue, conforme tabelas 1 e 2, a seguinte hierarquia decrescente: metrópole, capitais regionais e centro sub-regionais e centro de zona e locais. A tabela 15 traz a decomposição da variação do Ideb ${ }^{14}$ entre 2005 e 2011, mostrando a parcela de contribuição de cada componente do indicador - aprovação, nota de matemática ou nota de língua portuguesa. No EF 1, por exemplo, vemos que aproximadamente $37 \%$ do crescimento do Ideb em Fortaleza se deve ao aumento da aprovação média na etapa; quase $40 \%$ se deve ao aumento da nota em matemática e $24 \%$ em português.

Em ambas as etapas, houve melhoria do indicador de fluxo e de proficiência. Contudo, percebe-se que o crescimento do Ideb do EF 1 se baseia mais no aumento da proficiência, enquanto o do EF 2 no aumento da aprovação. Ademais, a proficiência em matemática tem maior participação no aumento do Ideb do que o desempenho em português no EF 1; o contrário ocorre no EF 2.

Por fim, vale notar que, no EF 1, a metrópole foi a região que menos apresentou aumento do Ideb e de seus subindicadores. No EF 2 foram os municípios classificados como capitais regionais e centro sub-regionais que apresentaram menor variação do indicador.

13 Para detalhes do cálculo do Ideb consulte a Nota Técnica número 1.

14 A metodologia de decomposição da variação do Ideb usada aqui foi desenvolvida com a ajuda de Simone Harnik, a quem gentilmente agradecemos. 

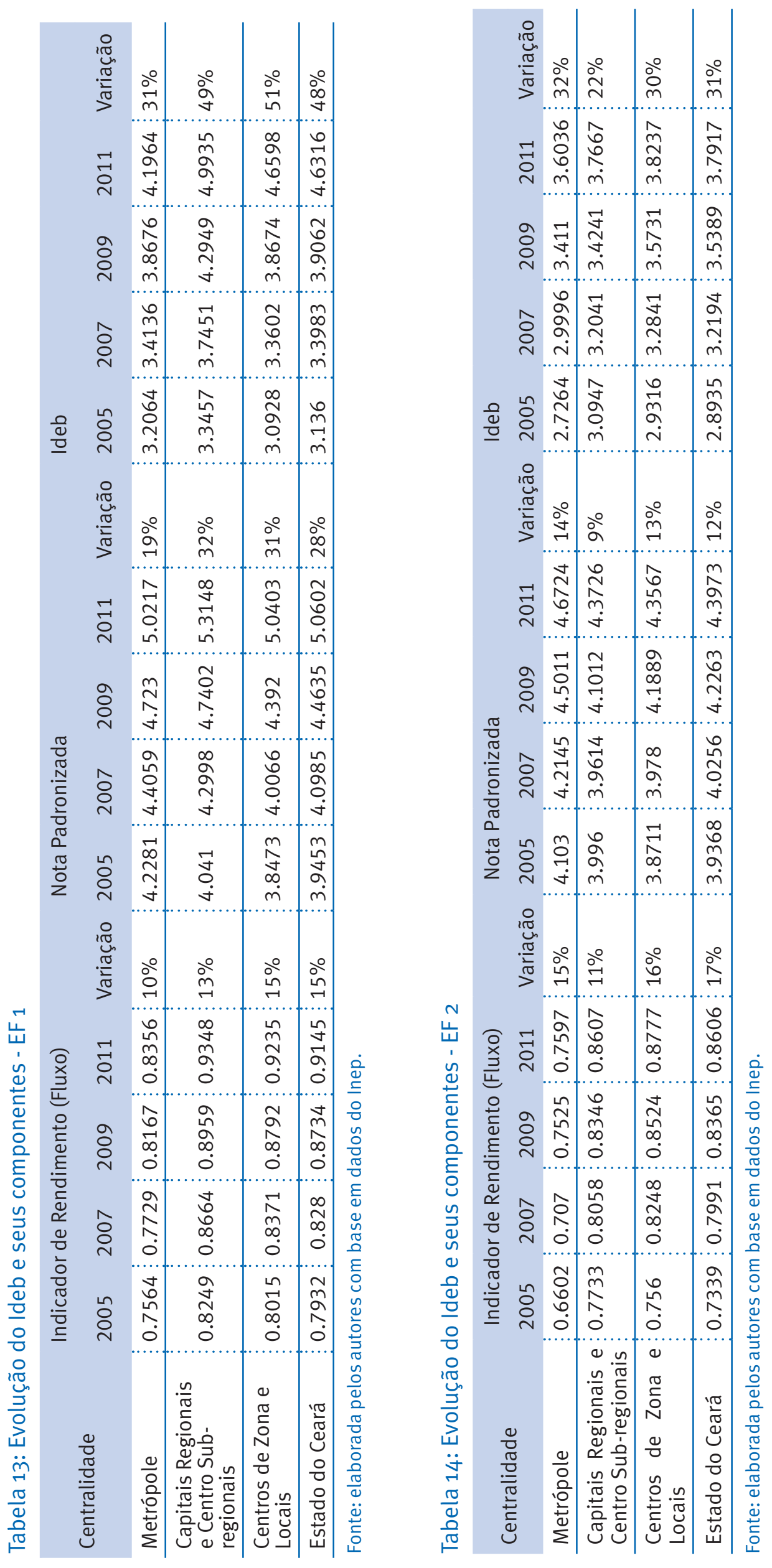


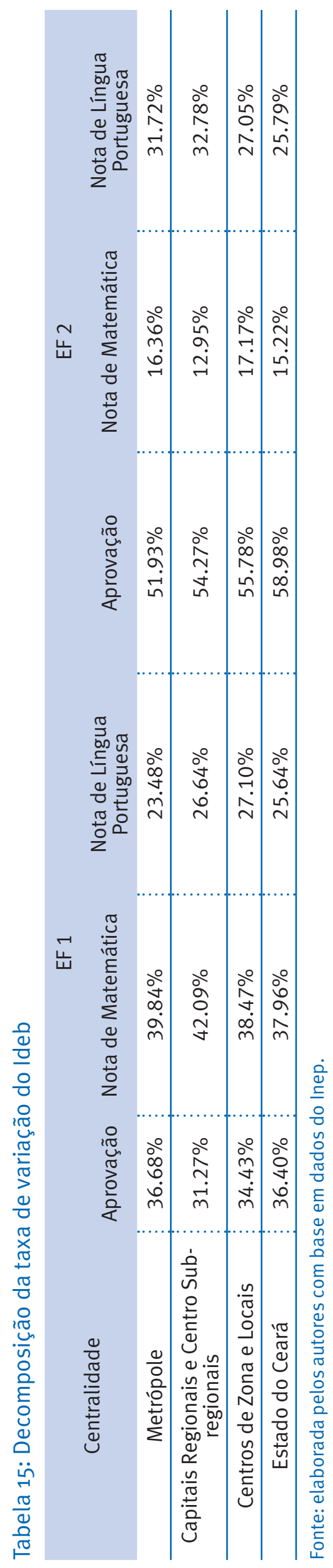




\section{CONCLUSÃO}

Este estudo procurou analisar a evolução do Ideb e a equidade no sistema educacional de ensino fundamental do estado do Ceará. Para tanto, realizou uma análise descritiva do Ideb entre escolas, entre municípios e entre Credes, entre 2005 e 2011. Caracterizou ainda a progressão dos níveis de equidade na rede, analisando a relação entre a evolução do Ideb e o nível socioeconômico das escolas e dos municípios, nos anos 2007 e 2011.

Os resultados mostraram um aumento da média sem aumento da dispersão do Ideb entre as escolas, municípios e Credes, no período analisado. Os dados revelam também um ganho de equidade no EF1, com redução do peso do NSE entre 2007 e 2011. No EF2, há evidência de melhoria da igualdade educacional apenas para os municípios classificados pelo IBGE como capitais regionais e centros sub-regionais. Os resultados de Fortaleza, em ambas as etapas do EF, destoam do padrão dos outros municípios, pois o peso do NSE na metrópole parece ser maior.

Ribeiro (2012), à luz de autores como Dubet (2009) e Santos (1979), evidencia que a equidade nas sociedades democráticas contemporâneas (que produzem permanentemente desigualdades e valorizam ao mesmo tempo igualdade e liberdade) somente pode ser fruto de uma política capaz de distribuir bens de modo a favorecer a população que tem menos recursos socioeconômicos.

Crahay (2002), após estudo baseado em pesquisas realizadas em vários países do mundo, afirma que a equidade na educação básica depende da capacidade do Estado de implementar políticas eficazes (sendo que, para ele, as pesquisas já evidenciaram quais são) e de adotar um sistema de pilotagem dessa implementação. Como exemplo de políticas e práticas educacionais mais eficazes quando o objetivo é a equidade, o autor cita aquelas que respeitam os distintos tempos de aprendizagem das crianças (evitando, portanto, a reprovação), que mantêm crianças com ritmos distintos nas mesmas salas (turmas heterogêneas), que adotam objetivos de aprendizagem claros num currículo estruturado (que denota as correspondências entre as aprendizagens), que oferecem estratégias de ensino segundo as necessidades das crianças, que contam com avaliações formativas explicitando aos alunos seus critérios e objetivos, dentre outras características. Ribeiro (2012), após analisar as duas redes de ensino 
municipais mais equitativas do estado de São Paulo, conclui que a existência de estratégias que permitem vincular ensino, aprendizagem e currículo estruturado é parte relevante do modelo de regulação dessas redes.

Ainda do ponto de vista do ensino e aprendizagem (a finalidade das políticas educacionais), segundo Bernstein (1984), as crianças de mais baixo nível socioeconômico tendem a ter maior sucesso em sua aprendizagem quando se adota uma pedagogia mais visível. Ou seja, uma pedagogia que explicita o processo de ensino e os critérios de avaliação usados pelo professor. Para o autor, a não explicitação desses elementos, cuja compreensão seria central para a aprendizagem, favoreceria apenas as crianças cujas famílias já dominam os códigos de funcionamento da instituição escolar. Afirmação compatível com as conclusões de Crahay (2002).

Os dados de pesquisa aqui apresentados, vistos à luz das reflexões acima sobre os vínculos entre equidade, políticas e práticas educacionais, colocam em evidência a necessidade de se compreender melhor as políticas que vêm sendo implantadas no estado do Ceará. Ou seja, os resultados deste trabalho indicam a relevância de se investigarem as variáveis que se vinculam aos mecanismos de gestão da educação consubstanciados na relação estado e municípios, por meio da ação das distintas Credes, municípios e escolas.

Essa discussão aponta para a importância da continuidade desta pesquisa de modo que perguntas sobre os desenhos e a implementação das políticas do estado do Ceará sejam respondidas. Há ou não, no estado do Ceará, um sistema de monitoramento das políticas para o ensino fundamental, capaz de detectar problemas e propor a revisão de procedimentos? Há objetivos de aprendizagem claros e esses objetivos são trabalhados junto aos professores?

O ensino está estruturado em torno desses objetivos? Há estratégias que conseguem efetivamente vincular ensino, aprendizagem e currículo? Que estratégias de regulação das redes de ensino têm sido implantadas pelas diferentes Credes e redes municipais ou estaduais? Em que elas se diferenciam entre si? Como é a pedagogia efetivada nas salas de aula?

Essas são algumas das muitas questões pertinentes para que seja possível compreender e identificar quais são as variáveis das políticas que explicam o comportamento do Ideb, a dispersão dos resultados e a equidade no sistema público educacional do estado do Ceará. Esse procedimento permitirá afirmar ou descartar a pertinência da nossa hipótese que relaciona 
a descentralização orquestrada com a evolução dos indicadores educacionais nesse estado.

No que diz respeito à discussão sobre equidade, será extremamente importante analisar sua evolução, incluindo, no modelo multinível, o NSE de cada aluno. Desse modo, será possível verificar se o nível de equidade do estado do Ceará está aumentando quando se apreende a capacidade de as escolas e redes educacionais fazerem com que os alunos, sobretudo aqueles de menor NSE, aprendam o que é necessário, independentemente do tipo de município em que vivem. 


\section{Quality and equity in Ceará's public basic school}

Abstract: This article tried to analyze Ideb's evolution and dispersion between 2005 and 2011 on both stages of State of Ceará's public basic school, as well as how this evolution has affected equity among schools between 2007 and 2011. Equity was analyzed considering schools' Ideb evolution in respect to their student body's average socio-economical level and distinct levels of centrality of the cities, according to a typology created by IBGE. The analysis indicate that schools', cities' and Credes '(regional agencies subordinated to State of Ceará's Secretary of Education) average Ideb has increased without corresponding dispersion increase in both stages of basic school. An increase in equity on initial years could be noticed, which was verified by a decrease of influence from socio-economical level to explain Ideb.

Key words: Education quality. Equity. Ideb. 


\section{REFERÊNCIAS}

ALVES, Maria Teresa G.; SOARES, José Francisco; XAVIER, Flávia P. Nível socioeconômico das escolas de educação básica do Brasil: Banco de dados versão 2. Belo Horizonte: Grupo de Avaliação e Medidas Educacionais (Game); São Paulo: Instituto Unibanco, 2012.

ASSOCIAÇÃO BRASILEIRA DE EMPRESAS DE PESQUISA. Critério de Classificação Econômica Brasil. Disponível em: 〈http://www.abep.org/novo/ Content.aspx?SectionID=84>. Acesso em: 1ํㅡㅁ nov. 2013.

BERNSTEIN, Basil. Classes e pedagogia: visível e invisível. Cadernos de Pesquisa, n. 49, p. 26-42, maio 1984.

BRASIL. Ministério da Educação. Instituto Nacional de Estudos e Pesquisas Educacionais Anísio Teixeira. Vencendo o desafio da aprendizagem nas séries iniciais: a experiência de Sobral/CE. Brasília: Inep, 2005. (Série Projeto Boas Práticas na Educação, n. 1.).

BROOKE, Nigel; SOARES, José Francisco (Orgs.). Pesquisa em eficácia escolar: origens e trajetórias. Belo Horizonte: Editora da UFMG, 2008.

CRAHAY, Marcel. É possível tirar conclusões sobre os efeitos da repetência? Cadernos de Pesquisa, São Paulo, v. 36, n. 127, p. 223-246, jan./abr. 2006. [Publicado originalmente como Peut-on conclure à propos des effets du redoublement? Revue Française de Pedagogie, n. 148, jul./set. 2004.]

. Poderá a escola ser justa e eficaz? Da igualdade das oportunidades à igualdade dos conhecimentos. Lisboa: Instituto Piaget, 2002.

DUBET, François. Les dilemmes de la justice. In: DEROUET, J. C.; DEROUETBESSON, M. C. Repenser la justice dans le domaine de l'éducation et de la formation. Lyon: Peter Lang, 2009, p. 29-46.

ÉRNICA, Maurício; BATISTA, Antônio Augusto Gomes. A escola, a metrópole e a vizinhança vulnerável. Cadernos de Pesquisa, v. 42, n. 146, p. 640-666, ago. 2012.

FUNDAÇÃO VICTOR CIVITA. (Org). Anos finais do ensino fundamental: aproximando-se da configuração atual. São Paulo, 2012. Disponível em: 〈http://www.fvc.org.br/estudos-e-pesquisas/2011/desafios-anos-finaisensino- fundamental-699874.shtml. Acesso em: 12 mar. 2012. 
GUSMÃO, Joana Buarque de; RIBEIRO, Vanda Mendes. Colaboração entre estado e municípios para a alfabetização de crianças na idade certa no Ceará. Cadernos Cenpec, São Paulo, v. 1, n. 1, p. 9-34, dez. 2011.

HANSEN, Bruce E. Lecture notes on nonparametrics 2009. Disponível em: 〈http://www.ssc.wisc.edu/ bhansen/718/718.htm〉. Acesso em: 1ํ nov. 2013.

IBGE. Censo Demográfico 2010. Rio de Janeiro: Instituto Brasileiro de Geografia e Estatística, 2007.

OLIVEIRA, Romualdo P. A qualidade do ensino como parte do direito à educação: um debate em torno dos indicadores. São Paulo: Universidade de São Paulo, Faculdade de Educação, 2010. Texto apresentado à banca de concurso para titular na Feusp. Mimeografado.

; ARAÚJO, Gilda C. Qualidade do ensino: uma nova dimensão da luta pelo direito à educação. Revista Brasileira de Educação, São Paulo, n. 28, p. 5-23, jan./abr. 2005.

PADILHA, Frederica V. Q.; BATISTA, Antonio Augusto Gomes. Evolução dos indicadores educacionais no Ceará: os anos finais do ensino fundamental. São Paulo: Cenpec, 2013. (Informe de Pesquisa n. 4.)

; BATISTA, Antonio Augusto Gomes; ERNICA, Maurício; PUDENZZI, Luciana. Os municípios e a qualidade das escolas na segunda etapa do ensino fundamental: as regularidades e as exceções do desempenho no Ideb. Estudos em Avaliação Educacional, São Paulo, n. 51, p. 58-81, jan./abr. 2012.

; PUDENZI, Luciana; ÉRNICA, Mauricio; BATISTA, Antonio Augusto Gomes. Os municípios e a qualidade das escolas na segunda etapa do ensino fundamental. São Paulo: Cenpec, 2011. (Informe de Pesquisa n. 1.)

PROGRAMA DAS NAÇÕES UNIDAS PARA O DESENVOLVIMENTO (Pnud). Atlas do desenvolvimento humano no Brasil 2013. Disponível em: «http://atlasbrasil. org.br/2013/download/`. Acesso em: 1ํ nov. 2013.

. Regiões de influência das cidades. Rio de Janeiro: Instituto Brasileiro de Geografia e Estatística, 2007.

RIBEIRO, Luiz Cesar Q.; KOSLINSKI, Mariane C. Efeito metrópole e acesso às oportunidades educacionais. Eure (Santiago), Santiago, v. 35, n. 106, dez. 2009.

RIBEIRO, Sérgio C. A pedagogia da repetência. Estudos Avançados, São Paulo, 
n. $12,1991$.

RIBEIRO, Vanda M. Justiça na escola e regulação institucional de redes de ensino do Estado de São Paulo. Tese (Doutorado em Educação) - Faculdade de Educação da Universidade de São Paulo, São Paulo, 2012.

SANTOS, Wanderley Guilherme dos. Cidadania e justiça: a política social na ordem brasileira. Rio de Janeiro: Ed. Campos, 1979.

SECRETARIA DA EDUCAÇÃO (SEDUC); FUNDOS DAS NAÇÕES UNIDAS PARA A INFÂNCIA (UNICEF). Regime de colaboração para a garantia do direito à aprendizagem: o Programa Alfabetização na Idade Certa (Paic) no Ceará. Fortaleza: Seduc, 2012.

SOARES, José Francisco. Análise dos pressupostos educacionais e estatísticos do Índice de Desenvolvimento da Educação Básica (Ideb). In: 10 ENCONTRO DE PESQUISA EM EDUCAÇÃO DA REGIÃO SUDESTE. Pós-Graduação em Educação na Região Sudeste em suas múltiplas dimensões. Anais... Rio de Janeiro, 2011.

RECEBIDO: Novembro de 2013.

APROVADO: Dezembro de 2013. 